\title{
Exploring the Real-Life Experiences of Regular Teachers Handling Children with Autism in Inclusive Setting
}

\author{
Rowena V. De La Cruz \\ SPED Teacher I, DepEd Employee No. 4671607, Saluysoy Integrated School, Philippines.
}

\begin{abstract}
How to cite this paper: Rowena V. De La Cruz. (2020). Exploring the Real-Life Experiences of Regular Teachers Handling Children with Autism in Inclusive Setting. The Educational Review, USA, 4(7), 135-149.

DOI: 10.26855/er.2020.07.001
\end{abstract}

Received: June 8, 2020

Accepted: July 20, 2020

Published: August 6, 2020

Corresponding author: Rowena V. De La Cruz, SPED Teacher I, DepEd Employee No. 4671607, Saluysoy Integrated School, Philippines.

Email:

rowenaisabeldelacruz@gmail.com

\begin{abstract}
Regular teachers assume an important role in educational setting; primarily they are responsible for ensuring that an adequate learning environment is established for children with autism who are in inclusive school programs. If the regular teachers' views and acceptance fail to reflect a deepened understanding about the disability, a less than favorable educational opportunity is risked for children with autism in this setting. In search for comprehensive and in-depth understanding, a descriptive phenomenological design was used to describe and explore the regular teachers' real-life experiences. It sought to establish: How do regular teachers describe their real-life experiences in handling children with autism in inclusive setting; and how they describe their role and extent of involvement in handling children with autism in inclusive setting based from their real-life experiences. Findings suggest that: There were different challenges faced by regular teachers and if not addressed properly, the same experiences will be experienced by other regular teachers who handle other disabilities in an inclusive setting and would cause a total failure of the program; even though they find inclusion program to be very hard and challenging it still creates a positive effect with which regular teachers adapts to change and improve or professionally develops themselves; and they believe that they are responsible for ensuring that an adequate learning environment is established for children with autism as well as other students who are in inclusive setting. A parallel study on the real-life experiences of inclusive education teachers handling other different disabilities is recommended.
\end{abstract}

\section{Keywords}

Inclusive setting, children with autism, inclusion program, real-life experiences

\section{Introduction}

The goals of education have shifted gears for children with special needs. Education is no longer simply about accommodating through strategies, routines and materials provided to the children in the least restrictive environment. It now ensures that all learners are included in the educational community. The idea of inclusion at the turn of the 21st century attracted intense and conflicting interests from educators and the public. The idea of including children with disabilities with regular children in the general education classroom gained increasing momentum on the concept and status of inclusive education and the role of the general education teachers changed as inclusion gained popularity 
which resulted to the acceptance of the general goal for educating all students with disabilities was inclusion (Osgood, 2005).

There are many factors that affect the idea of inclusive education for students with disabilities. Among these factors are the perception and acceptance of regular teachers in an inclusive setting. Robbins (2014) indicated that one of the key elements in the successful implementation of the policy is the perception and the acceptance of the people who have the major responsibility for implementing it, the teachers, which developed through their experiences. Oliger (2013) added that experiences, trainings and attitudes of the regular teachers impacted the effectiveness to include the children with special needs into the general classroom.

Educational placements for children with special needs including those with autism are anchored in Inclusive Education (IE). Formalized in the 1994 Salamanca Declaration and DepEd Order No. 26, s. 1997, IE takes its cue from the normalization ideology. Normalization is a systematic process of providing students with special needs the needed training and opportunities given their normal counterparts enabling them to maximize their potential, achieve some degree of independence in leading their lives, access and participate in the benefits of their community (Arnilla, 2015).

Although inclusion has already become a worldwide approach, many teachers have different responses towards putting children with special needs in the mainstream classroom. Numerous researches have been made to study the attitudes of teachers toward inclusive education all over the world. The results of these studies vary from negative to positive; results which are affected by numerous factors such as: economic status of the country; availability of resources; child-variable; and teacher factor (Fortain, 2015).

According to Haaland (2011), teachers' beliefs, perceptions, attitudes and acceptance toward students with special needs are often the most critical aspect to change the classroom. It was supported by Sprowl-Loftis (2013) that teachers play a vital role in student's education whereby their attitudes are seen as a major element which can be formed through experiences or contact with the students with disability. Their view to the concept of inclusion affects how they will implement the said development. In addition, studies have found evidence indicating that educators with more positive beliefs about inclusion report greater use of effective inclusive practices and supports than those with less positive attitudes (Fortain, 2015).

Regular teachers assume an important role in educational setting. They are primarily responsible for ensuring that an adequate learning environment is established for children with autism as well as other children with disabilities who are in inclusive school programs. Understanding the impact, autism has on social and an academic life of individuals is of utmost importance because of the complex educational needs this could pose for classroom instruction. Additionally, the people with the direct contact with children with autism including the regular teachers are responsible for their growth and development toward successful independence in society. If the regular teachers' views and acceptance fail to reflect a deepened understanding of the said disability, a less than favorable educational opportunity is risked for the children in this setting.

For this reason, it is crucial to study and describe the real-life experiences of regular teachers handling children with autism and sought to establish: 1 . How do regular teachers describe their real-life experiences in handling children with autism in inclusive setting; and 2. How they describe their role and extent of involvement in handling children with autism in inclusive setting based from their real-life experiences.

\subsection{Review of Related Literature and Studies}

This section presented the review of related literature and studies both local and foreign which are relevant in studying the lived experiences of regular teachers handling children with autism in inclusive setting. It was divided into three sections: the concept of inclusive education, the children with autism \& the inclusive education program and the regular teachers' experiences on top of inclusive education program.

\subsubsection{The Concept of Inclusive Education}

There are several definitions of inclusion. All definitions seem to agree that inclusion is the learning of students with disabilities with their non-disabled peers in a general education setting (Solis et al., 2012). This means that students with disabilities participate in all classroom routines, structures and activities and students no longer leave the classroom for additional support, rather, support is brought into the classroom.

According to Inciong et al. (2007), inclusion is a process by which a school accepts children with special needs for enrolment in regular classes where they can learn side by side with their peers. The school organizes its special education program and includes a special education in its faculty. The school provides the mainstream where regular teachers and special education teachers organize and implement appropriate programs for both special and regular students.

The concept of Inclusive Education here in the Philippines is based from the Department of Education (DepEd) Order 
26, series of 1997 also known as the Institutionalization of Special Education Programs in Elementary and Secondary Schools Level in support to the implementation of the Republic Act 7277 (Magna Carta for Disabled Persons). To achieve the target set for the Asian and Pacific Decade of Disabled Persons (1993-2002) that $75 \%$ of the 4 million children with disabilities should be provided equal educational opportunities, special education for the said type of students shall be institutionalized in all schools, both in elementary and secondary. The Institutionalization aims to provide access to basic education among children with special needs through the formal system and other alternative delivery services in education.

The following are the guidelines which observed in the institutionalization of special needs education: (lifted from DepEd Order No. 26 series of 1997).

(a) All divisions shall organize at least one SPED Center which will cater to children with special needs. Programs organized shall adopt the inclusive education concept or the different types of SPED programs suited to the needs of the learners. The Center shall function as a Resource Center to support children with special needs integrated in regular schools, to assist in the conduct of in-service-training, to produce appropriate teaching materials; and to conduct continuous assessment of children with special needs. School divisions shall appropriate funds for the aforementioned activities.

(b) All districts shall organize SPED programs in schools where there are identified children with special needs. Assistance from existing SPED Center shall be sought in the assessment of the children with special needs and in the orientation or training of the regular teachers to help these students. Teachers and administrators who have had trainings in SPED shall be identified and their expertise tapped.

(c) Local trainings at the regional, division and district levels shall be initiated and conducted by the identified Regional Trainers in Special Education.

(d) To sustain the continuing interest of supervisors, administrators and teachers in the implementation of the SPED programs, incentives shall be planned and provided for.

(e) To ensure that the education of children with special needs is an integral part of the educational system, an annual allocation for extension position shall be provided for SPED teachers.

Educational placements for children with special needs including those with autism are anchored in Inclusive Education (IE). Formalized in the 1994 Salamanca Declaration and DepEd Order No. 26, s. 1997, IE takes its cue from the normalization ideology. Normalization is a systematic process of providing students with special needs the needed training and opportunities given their normal counterparts enabling them to maximize their potential, achieve some degree of independence in leading their lives, access and participate in the benefits of their community (Dizon, 2000 in Arnilla, 2015).

There have been issues raised on the success of inclusive education in the Philippines across all special needs categories. Dizon (2013) argued that mere placement of these children in classes with typically developing/regular children do not account for inclusion. They must be educated as well.

For students with special needs, Dizon (2000) in Arnilla (2015) described educational placement concerns as an education intervention that synchronizes with the student's increasing needs: from external to internal control; from shortterm to long-term; and from segregation to integration. The progression is prompted as the student grows in skills and acquires maturation.

According to Sprowl-Loftis (2013), in establishing programs for students with disabilities in inclusive classrooms, several factors should be included such as planning, appropriate resources, monitoring and documenting progress, general education teachers attitudes toward inclusion, training, knowledge of educating students with disabilities, and experience with special needs students.

Oliger (2013) studied the Elementary Teachers’ Perspectives of Inclusion in the Regular Education Classroom, findings suggest that teachers and administrators recognition of the barriers that interfere with their ability to meet the needs of students with special needs, an understanding that successful inclusion requires teamwork between general and special education providers and that inclusion in the general education environment may not be appropriate for all students.

In addition, in the study conducted by Stilth (2013) entitled Principals Attitudes toward Inclusion of Students with Disabilities, results suggest that it is critical that all stakeholders are involved and knowledgeable in order to have a successful inclusion program in the school. Each stakeholder must have the opportunity to identify practices that they feel will make inclusion work.

Balboa (2014) supported the above-mentioned studies in his study entitled Perceptions of Regular Children towards Inclusion of Children with Special Needs in Selected Private Regular Schools in Metro Manila. The participants of the study, comprising 62 parents of regular students in different private schools within Metro Manila, revealed that they 
generally have positive perceptions on the inclusion of children with special needs in private schools. They view inclusion as a beneficial educational philosophy for their children as they described the children's development in the personal, socio-emotional and academic domains. They most firmly believe that inclusion is helpful in positively developing the regular children's care and friendship with peers with disability. The participants also generally support inclusion in private schools in the country for they believe that its benefits outweigh its risks. It was noted that as long as schools maintain good educational philosophies and standards with competent staff members to handle the negative behaviors of children with special needs, the attitude of parents with regular children remains positive.

Research studies above suggested that if inclusion will be successfully implemented, it must become integrated into the entire education system to meet the various needs of all students especially the students with special needs and collaboration on the part of all persons including the support for regular teachers who serve the students because the degree of support and assistance and vision was the most powerful predictor of the success of the program. If this will happen, inclusion will not just be a mandated concept but can become a reality.

\subsubsection{The Children with Autism and the Inclusive Education Program}

Social acceptance by nondisabled or regular students as argue by the some proponents of inclusion is one critical aspect in favoring inclusion. In line with this argument according to Fortain (2015), positive attitudes have been found to play an important part in effective inclusive education. Studies revealed that the positive attitude of both regular teachers and regular students included in inclusive classrooms is the greatest source of success for inclusive education (Allison, 2011)

According to Abner (2013), the characteristics of autism vary in each child due to the severity of the case. Children can exhibit the behaviors in different combinations and different degrees of severity and the development of children with autism may take place more gradually and erratically, with unforeseen gaps in understanding. In general, children with autism have less opportunity to learn incidentally, in the manner that regular children do. Therefore, children with autism may need to be deliberately taught skills that regular children pick up intuitively.

In the study conducted by Saunders (2012) revealed that by enhancing the degree of training required of general education teachers, they may become more familiar with the needs of students with disabilities such as autism. This does not mean eliminating educational specialists; rather, it means providing a stronger base of knowledge as a starting point for general education teachers. The results of this study clearly indicated that inclusion was made possible through the active collaboration or partnership between the program director for students with disabilities and general educator teachers. This must continue as a normal part of lesson preparation and professional development. Parents of children with autism should have every expectation that educators will strive to include their children in the academic and social milieu of a school. As principled and reflective educators, we should expect nothing less than a concerted effort to meet these expectations and make inclusion a reality.

Research studies suggested that the attitudes and acceptance of the regular students on the inclusion of students with disability especially to the children with autism merely depends on their past experiences and contact with them. Additionally, meaningful interaction with the students with disabilities is the key element in contributing to positive attitudes that might lead to successful implementation of inclusive education program. Inclusion of children with autism might not be easy to achieve but it can be an achievable goal. For this to happen, the school, students, school administrators and general education teachers must actively collaborate to meet the needs of the children with autism.

\subsubsection{The Regular Teachers' Experiences on top of Inclusive Education Program}

According to Haaland (2011), teachers' beliefs, perceptions, attitudes and acceptance toward students with special needs are often the most critical aspect to change the classroom. It was supported by Sprowl-Loftis (2013) that teachers play a vital role in student's education whereby their attitudes are seen as a major element which can be formed through experiences or contact with the students with disability. Their view to the concept of inclusion will affect on how they will implement the said development. In addition, studies have found evidence indicating that educators with more positive beliefs about inclusion report greater use of effective inclusive practices and supports than those with less positive attitudes (Bender, Vail, \& Scott, 1995 in Fortain, 2015).

According to Heger (2011), experiences of people with contact with disabled students including the teachers are considered significant because of their relationship to their attitudes. Beasly (2012) found that people with more positive experiences had a more positive attitude toward students with disabilities. This research study suggests that experience working with students with disabilities may have some relationship to the attitudes of the teachers towards inclusion.

Although inclusion has already become a worldwide approach, many teachers have different responses towards putting children with special needs in the mainstream classroom. Numerous researches have been made to study the attitudes of teachers toward inclusive education all over the world. The results of these studies vary from negative to 
positive; results which are affected by numerous factors such as: 1) economic status of the country; 2) availability of resources; 3) child-variable (i.e. the kind and severity of disability); and 4) teacher factor (Fortain, 2015).

Sutton (2013) studied Teachers’ Attitudes toward inclusion of students with Disabilities, findings showed that teachers with more years of experience teaching regular and special education students had more positive attitudes towards inclusion. This is significant in that prior experience and training both influence a teacher's attitude towards inclusion. The more training teachers received the more positive their attitudes were towards inclusion.

In the study conducted by Allison (2011) entitled the Lived Experiences of General and Special Education Teachers in Inclusion Classrooms: A Phenomenological Study, findings from the study revealed that the participants encountered both positive and negative experiences in the inclusion setting which clearly impacted their attitudes and beliefs about inclusion. In general, both general education teachers and special education teachers believed that administrative support, mutual respect, a positive work environment, and open minds towards inclusion, professional development opportunities, and knowledge of students with disabilities are all crucial components needed to successfully implement inclusion.

Haaland (2011) in his study entitled A Phenomenological Study of Teachers' Experiences of Students with Learning Disability in Mainstream Middle School Classrooms, results revealed that the participants described feeling unprepared to handle the drastic differences in ability within a single inclusion classroom; however, they also demonstrated a vigorous willingness to accommodate the needs of learning disabled students with a desire for additional knowledge and experience that would directly facilitate creative strategies for enhancement of student outcomes. The participants of this study also noted the importance of collaborative interaction. However, significant time restrictions, both their own as well as that of the special education or resource teachers, were believed to limit these collaborative efforts. In addition, participants who were involved in team teaching models suggested the positive aspects of the team teaching model in terms of increased collaboration through frequent and open discussion between team teachers. Perceived by most participants, the safe learning environment was primarily affected by the positive attitudes of teachers and administration, despite limited availability of resources and information. Participants also revealed the perceived importance of parental and societal behavioral expectations and the intolerance of negative behavior towards others.

Robbins (2014) studied the Experiences of General Education Elementary Inclusion Co-Teachers in Successful Schools: a Phenomenological Study, using the words of the 13 participants from their in- depth interviews, journals, and focus group, four themes emerged. They were (a) putting forth the effort to be life-long learners, (b) valuing the power of relationships, (c) thriving off of student success, and (d) setting aside frustrations and understanding the big picture.

In contrast with the first studies, in the study conducted by Sutton (2013) entitled Teacher Attitudes of Inclusion and Academic Performance of Students with Disabilities, findings of this study indicated that professional development, years of inclusion teaching experience, and college preparation do not have a significant relationship with teachers' attitudes of student performance. According to Cramer's (2014) study entitled the Pre-service Teachers' Attitudes and Efficacy Beliefs toward Inclusion of Students with Autism Spectrum Disorders in the Midwestern Region of the United States revealed that pre-service teachers have positive attitudes toward inclusion of students with ASD. However, their efficacy beliefs about their ability to educate students with ASD in an inclusive classroom were low which is associated with their experience and preparedness.

Overall, the available literature and studies about the teachers' handling children with autism in an inclusive setting gave information on the limitations of special education programs and services for students with special educational needs specifically the inclusion program for the children with autism.

As shown by the various studies, the success of the implementation of the inclusion program of a school depends on the attitudes of the people with the direct contact with the children with autism as affected by their experiences including the regular teachers. Also, based from the studies, social acceptance of the regular students, collaboration and meaningful interaction of students and teachers and the degree of the administrative support and support are the sub-factors that contribute to the success of the inclusion program. If this will happen, inclusion will not just be a mandated concept but can become a reality.

\section{Conceptual Framework}

The diagram presented in Figure 1 entitled conceptual framework of the study shows the lived experiences of regular teachers handling children with autism in inclusive setting.

The conceptual framework of the study was based on the Theory of Experience by John Dewey (1938) and Choice Theory by Glasser (1998).

The inclusion program in public schools was introduced and implemented through the Department of Education (DepEd) Order 26, series of 1997 also known as the Institutionalization of Special Education Programs in Elementary 
and Secondary Schools Level in support to the implementation of the Republic Act 7277 (Magna Carta for Disabled Persons). The inclusive setting is composed of students with disability, regular students and regular teachers.

The regular teachers are the key component in determining the success or failure of educating students with disabilities in inclusive setting. Sprowl-Loftis (2013) added that regular teachers play a vital role in student's education which can be formed through experiences or contact with the students with disability. Regular teachers in inclusive setting may encounter positive and negative experiences which may clearly create impact in their attitudes and beliefs about inclusion.

Moreover, social acceptance by the regular students as argue by the some proponents of inclusion is one critical aspect in favoring inclusion. Research studies suggested that the attitudes and acceptance of the regular students on the inclusion of students with disability especially to the students with autism merely depends on their past experiences and contact with them. In addition, studies revealed that the positive attitude of both regular teachers and regular students included in inclusive classrooms is the greatest source of success for inclusive education (Allison, 2011)

Through the interaction of regular teachers with regular students and students with autism in inclusive setting in public school will create and lead to a meaningful lived experiences.

Experience, as treated by Dewey (1938), is unlike the common use of the term as referring to participation in events or activities and, in the process, having certain feelings. Instead, experience is a category of thinking, a minimal unit of analysis that includes people (their intellectual, affective, and practical characteristics), their material and social environment, their transactional relations (mutual effects on each other), and affect. Thus, experience is not something concealed within individuals, but extends in space and time across individuals and setting in the course of temporally unfolding societal relations, which themselves are per fused with affect.

According to SAGE Encyclopedia of Methods of Research (2008) in Arnilla (2015), lived experience refers to a representation and understanding of a researcher or research subject's human experiences, choices and options and how those factors influence one's perception of knowledge. It speaks to the personal and unique perspective of researchers and how their experiences are shaped by subjective factors of their identity including race, class, gender, sexuality, religion, political associations and other roles and characteristics that determine how people live their daily lives.

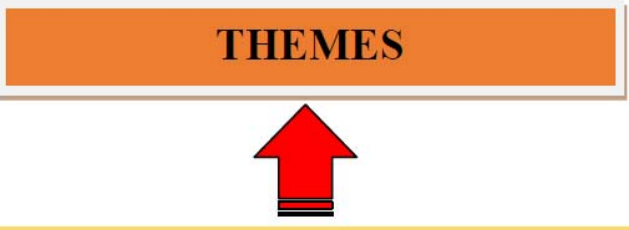

\section{REAL-LIFE EXPERIENCES}

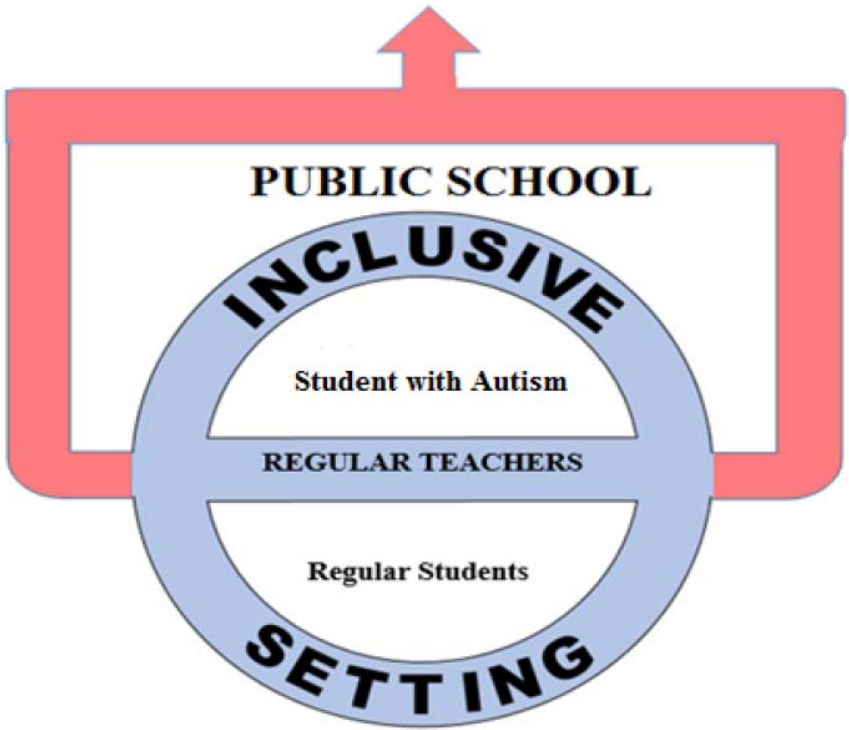

Figure 1. Conceptual Framework (De la Cruz, 2017). 
Included in this theory are the teachers' abilities to feel competent in their quality worlds. Glasser's (1998) choice theory defines an individual's quality world as a small personal world which each person starts to create and re-created throughout life through a small group of specific pictures. These pictures fall into three major categories, including "the people [they] want to be with, the things [they] want to own or experience, and the ideas and beliefs that govern [their] behavior".

In addition, building strong relationships with individuals can only foster the quality world of a person. The author also concluded that individuals were responsible for their own thoughts and actions. The concept of a quality world forms the conceptual framework of this study because the author and the theory propose that individuals choose to develop attitudes and beliefs about situations based upon lived experiences. Therefore, teachers' attitudes and beliefs about inclusion may be determined by their experiences in the educational setting. The concept of a quality world pertains to this study because the goal of this study is to understand the lived world of human experience in relation to the inclusion setting.

In summary, Glasser's (1998) choice theory examined the following three conceptual constructs in relation to an individual's quality world: (a) the people with whom individuals want to be; (b) the things that individuals want to own or experience; and (c) the ideas and beliefs that govern an individual's behavior. It is noted that positive interpersonal and personal relationships foster the quality world of an individual. Therefore, the theory and other current research studies support the conceptual framework for this study because individuals choose to develop positive or negative perceptions and attitudes about a situation based upon their real-life experiences.

\section{Research Questions}

This research aims to describe the real-life experiences of regular teachers handling children with autism in inclusive classroom setting and specifically, it sought to answer the following questions:

1. How do regular teachers describe their real-life experiences in handling children with autism in inclusive setting?

2. How do they describe their role and extent of involvement in handling children with autism in inclusive setting based from their real-life experiences?

\section{Methodology}

\subsection{Research Design}

This study was qualitative in nature and uses descriptive phenomenological approach to describe and explore the real-life experiences of the ten (10) regular teachers handling children with autism in an inclusive setting of Saluysoy Integrated School. The descriptive phenomenological design was used to get a comprehensive and in-depth understanding of the regular teachers' real-life experiences as they interact, socialize and accommodate the children with autism and how these experiences affect their attitudes. The rationale for using descriptive phenomenological method is based on the constructivist philosophical quality that concerns itself with how complex socio-cultural issues are experienced, interpreted and understood by individual people, in individual contexts, and at particular points in time (Bloomberg, 2008). In order to gain a holistic understanding of the regular teachers' real-life experiences in handling children with autism, the researcher will acquire thick description of their real-life experiences through individual in-depth interview that will helped the researcher probe the real-life experiences used by the regular teachers in inclusive classroom setting. Bloomberg (2008) added that descriptive phenomenological design focuses on discovery and description with its major objective to capture the meaning of experience.

Moreover, the study uses Moustakas (1994) in Zeeck (2012) four descriptive phenomenological intertwining steps or phases to describe and understand the phenomenon on the real-life experiences of regular teachers in handling children with autism in an inclusive classroom setting which involves the epoche, phenomenological reduction, imaginative variation and synthesis.

\subsection{Respondents}

The study focused on the regular teacher of Saluysoy Integrated School as respondents because of their direct contact with the children with autism, the researcher believed that they will be the key elements in understanding the phenomenon of inclusion of children with autism in the inclusive classroom setting in Saluysoy Integrated School—Meycauayan City.

\subsection{Sampling Method}

The study employs purposive sampling method in choosing respondents for the study. The following will be the cri- 
teria set and will be used by the researcher for the study: a) regular teachers from Saluysoy Integrated School; b) those who have at least two years of active and ongoing experience in teaching and accommodating the children with autism in a regular classroom setting; c) male or female; d) ages ranged from twenty to sixty years; e) who have had between one to twenty years of teaching experience; f) with or without proper training and seminar on teaching children with autism; and g) regular teachers in mainstream or inclusive classroom setting.

\subsection{Source of Data}

The source of data for this study was obtained from the in-depth interview of the teachers handling children with autism in an inclusive setting within Saluysoy Integrated School using a descriptive phenomenological design.

Based on the standards of descriptive phenomenological design, the distinct features and procedures of this phenomenology study will fit well with this study. The features that made this a good fit will include (a) understanding the processes of how events and actions in the classroom happened, (b) developing contextual understanding through rich description, (c) facilitating interactivity between researcher and participants, (d) adopting an interactive view, and (e) maintaining design flexibility (Bloomberg, 2008).

\subsection{Instrument}

In this phenomenological study, an individual in-depth interview was used to gather data from the regular teachers handling children with autism in inclusive setting using an interview guide (see Appendix A). In-depth interviewing is a powerful way to gain insight into educational and other important social issues through understanding the lived experience of the individuals whose lives reflect those issues. As a method of inquiry, in-depth interviewing is most consistent with people's ability to make meaning through language. It affirms the importance of the individual without denigrating the possibility of community and collaboration. Finally, it is deeply satisfying to researchers who are interested in others' stories. Seidman (2006) further argues that interviewing provides access to the context of people's behavior and thereby provides a way for researchers to understand the meaning of that behavior. A basic assumption in in-depth interviewing research is that the meaning people make of their experience affects the way they carry out that experience.

The interview guide was divided into two parts. The first part is about the demographic profile of the respondents and the second part is for the participants' lived experiences and their role and extent of involvement in handling children with autism based on the research questions and conceptual framework of the study.

In validating the said instrument, the interview guide was submitted to a specialist within the Schools Division of Meycauayan City. Also to optimize the validity of the study, it will use a validity strategy called Member Check. The process of Member Check which is also referred to as member or respondent validation, as stated by Sandelowski (2008) in Arnilla (2015) is a strategy most often used to optimize the validity of qualitative research. Creswell (2014) in Arnilla (2015) explained that member check determines the accuracy of the qualitative findings through taking the final report or specific descriptions or themes back to the respondents and determining whether these respondents feel that they are accurate. The researcher will contact the respondents through their mobile number or e-mail. Then, the researcher will be conducting a follow-up interview to the member check respondents and the member check respondents will check the themes that incorporated in the study.

\subsection{Data Collection Procedure}

The data collection was conducted through an individual in-depth interview with regular teachers handling children with autism. The researcher will be developing an interview guide (see Appendix A) and will be schemed, checked and validated by a specialist within the Schools Division of Meycauayan City. The individual in-depth interview will be supplemented by other pertinent data sources as part of the data collection process. Engaging in data collection process will lead to a more valid, reliable and diverse construction of realities which will facilitate deeper understanding about the study.

Prior to the actual individual in-depth interview process, the researcher will be asking permission (see Appendix B) from the school administrators and respondents to videotape or digitally record each interview for validity and purposes of rigor through a brief orientation meeting facilitated by the researcher. All videotaped/digitally recorded interviews will be transcribed verbatimly. All respondents will be given codes to ensure their confidentiality. The researcher will followed the rapport building and interview protocols as determined by the principal or other administrators of the school. The in-depth interview time and venue will be scheduled in coordination with the school principal or other school administrators. Lastly, after the interview, the researcher will be guided by Lofland's common sense rules on disengagement which includes: 1) avoiding to leave abruptly; 2) saying goodbye personally; 3) promising to keep in 
touch; and 4) keeping in touch as a situation dictated (Arnilla, 2015).

\section{Results and Discussion}

\subsection{Theme No. 1: Perception about Inclusion}

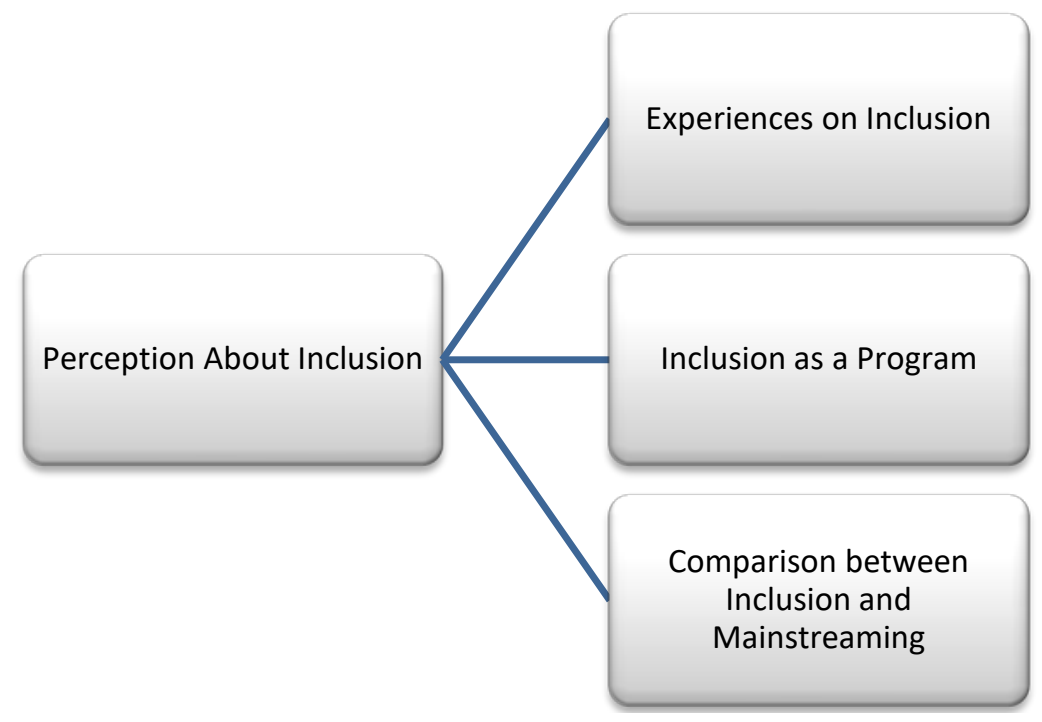

Figure 2. Perception about Inclusion.

\subsubsection{Experiences on Inclusion}

To understand the implementation of inclusion, we have to recognize what is not accurate about inclusion as a program. The participants discovered that what others say about Inclusion is easy as 1-2-3 were not true based from their experiences. The participants debunked this and shared their ideas based from their experiences and based from the shared experiences of the ten (10) participants, they agreed that inclusion is not as easy as other think but rather a very challenging program that requires effort, patience, trainings and finding alternative ways or back up plans. Difficulties and problems were encountered as experienced by the participants as they engage themselves in the said program. As stated by Sears (2016), problems and dilemmas happened during the implementation of inclusion program when teachers felt vulnerable and not ready for the program.

\subsubsection{Inclusion as a Program}

Some researchers stated that inclusion only benefits children with special needs, but the ten (10) participants of this study claimed otherwise as they shared their ideas based from their real-life experiences, they agreed that inclusion benefits both children with disabilities and the regular students. In inclusion program, the regular students acquired positive perception, attitudes, acceptance, respect and friendship towards children with autism. This setting promotes the belief that all students have the right to learn together despite of disabilities and differences. As Green (2017) shared that inclusion is a very challenging program that requires an increased emotional, personal, and professional capacity and dedication from the teachers. The author continued that there were benefits in including students with disabilities in general education classes: an overall belief that inclusion benefitted all people involved wherein it created a social benefit for students with or without disabilities.

\subsubsection{Comparison Between Inclusion and Mainstreaming}

Another perception in understanding the implementation of inclusion is to determine the knowledge about the concept of inclusion and mainstreaming. The following are the ideas shared by the participants as they compared the concept of inclusion to mainstreaming. Four (4) participants who were aware about special education compare inclusion and mainstreaming correctly, giving meaning that trained teachers understand completely the two concepts being compared. It was supported by Solis et al. (2012) that trainings and experiences are relative in understanding the concept of inclusion and mainstreaming. They continued that the limitations of regular teachers in their understanding of inclusion and mainstreaming were associated with such factors as: a lack of undergraduate training in teaching students with learning disabilities; a lack of formal certification in relation to educational background and training; and a lack of professional development on inclusion. 


\subsection{Theme No. 2: Challenges Incurred in Handling Children with Autism}

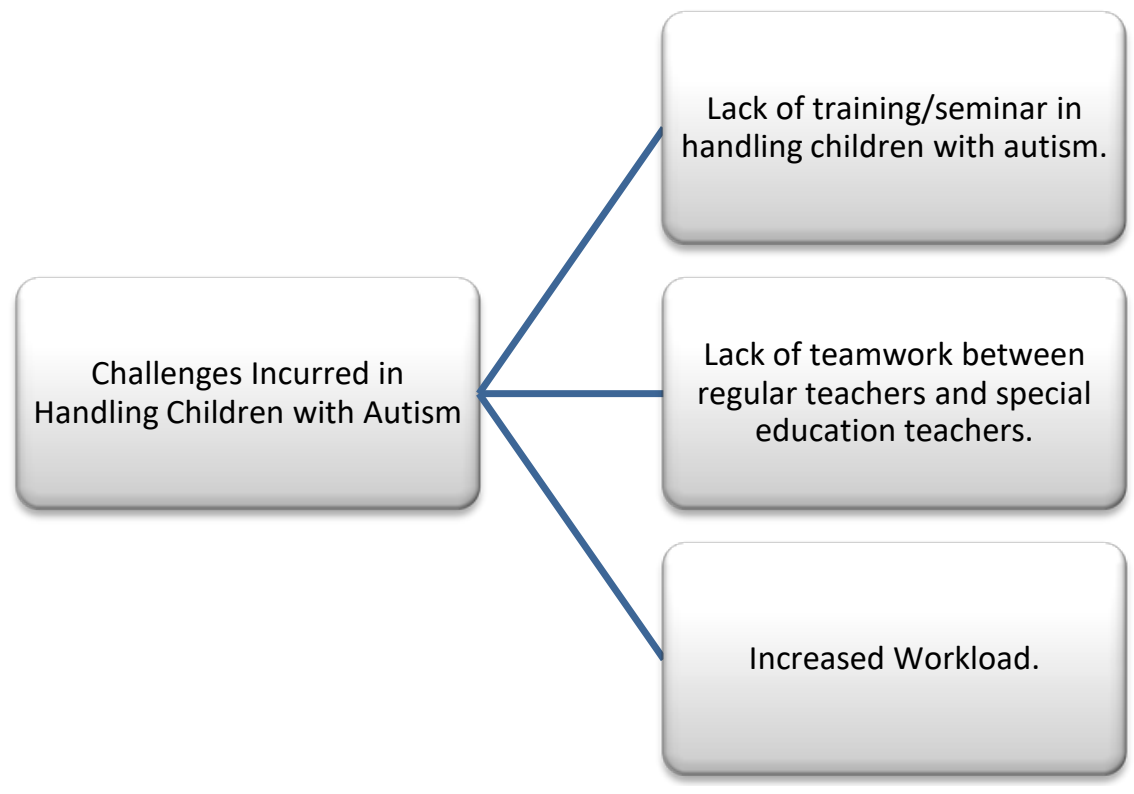

Figure 3. Challenges Incurred in Handling Children with Autism.

\subsubsection{Lack of Training or Seminar in Handling Children with Autism}

Lack of training or seminar in handling children with autism is an issue identified by the regular teachers as a part of challenge they often incurred in an inclusive setting. This issue was mentioned multiple times in the transcript of interviews of the ten (10) participants. All of the regular teachers in this study admitted that they had not received any training related to special education that could guide their instructional planning. Participants agreed that lack of quality training attributes to lower successful rate of the inclusive education program.

It is said to be that training and preparation are very important for the regular teachers before they bring into inclusive setting. This was because past research showed that lack of training among inclusive teachers resulted to teachers with negative attitudes and unsuccessful learning among students with special needs (Forlin \& Chambers, 2011). They added that lack of teachers' training could have contributed to their misconceptions of students' disabilities. In Robbins (2014), he explained that there were specific elements that need to be in place for successful inclusion including training for the teachers, Oliger (2013) added that experiences, trainings and attitudes of the teachers impacted the effectiveness to include the children with special needs into the general classroom. Furthermore, Sutton (2013) added that the more training teachers received the more positive their attitudes were towards inclusion.

\subsubsection{Lack of Teamwork Between Regular Teachers and Special Education Teachers}

Lack of teamwork, is another challenges faced by the regular teachers toward inclusion. Most of the participants found it as a problem in creating an environment of teamwork between themselves and special education teachers. Collaboration or teamwork is defined as the on-going, interactive process of two co-equal education professionals with differing areas of expertise who work together toward a common goal (Robbins, 2014). Based from the shared real-life experiences of the participants with regards to the lack of teamwork amongst regular teachers and special education teachers causes a gap in understanding how inclusion program is carried out and is implemented in the school, with lack of teamwork, it can result to unsuccessful implementation of inclusion program.

\subsubsection{Increased Workload}

The participants of this study considered implementation of inclusive education resulted to an increase on their workload and considers it as one of the challenges inclusive education based from their real-life experiences. Inclusion program requires the regular teachers to work more time with students with or without disabilities and more time for preparations and planning. They felt that they needed more time to prepare to teach the children with autism which consume most of their time. Sears (2016) pointed that paperwork has long been recognized as a trouble spot in the implementation of inclusive education. While Abner (2013) added that the additional workload during the implementation of the program developed negative attitudes and views of the regular teachers towards the program. 


\subsection{Theme No. 3: Regular Teachers’ Role in an Inclusive Setting}

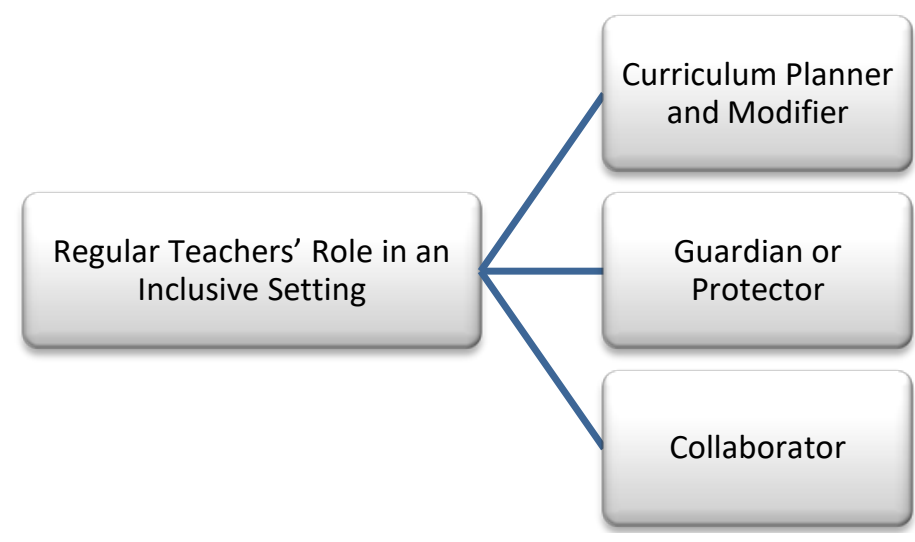

Figure 4. Regular Teachers' Role in an Inclusive Setting.

Two participants revealed that to meet the specific needs of children with autism, they have to carefully plan and modify the curriculum, as well as the instructional materials and strategies to make the learning possible. Another role a regular teacher plays inside an inclusive classroom setting is as a guardian or protector of children with autism against discrimination and bullying. These instances are unavoidable because these children's' differences, it can happen to any children with disability. While the remaining six participants think that their guardian or their protector against bullies, from bullying and discrimination. Lastly as a collaborator, who works and ask supports with other people, to merge knowledge, experience and skills with other professionals or teachers to meet the common goal for children with autism. Supports from other teachers and professionals are most valuable for inclusive education to make the implementation of this program successful. According to Ely (2013), inclusive teacher holds up to twenty roles and responsibilities within a given school year that focus on special needs students and inclusive support systems such as co-teaching, collaborative teaching, administration services. While in Abner (2013), the role of the inclusion teacher is complex and multifaceted. The research identified the changing roles of the regular teacher, ranging from being a learning disability resource teacher, to a novice inclusion teacher, and then finally an expert inclusion specialist. The results implicated that the shift in responsibilities within each role became progressively more detailed and time consuming in regard to teaching, consultation, interpersonal skills, and assessment practices. Thus, the inclusive educator of today must be prepared for the roles and responsibilities that are handed to them within their position in their classroom.

\subsection{Theme No. 4: Opportunities Acquired in an Inclusive Setting}

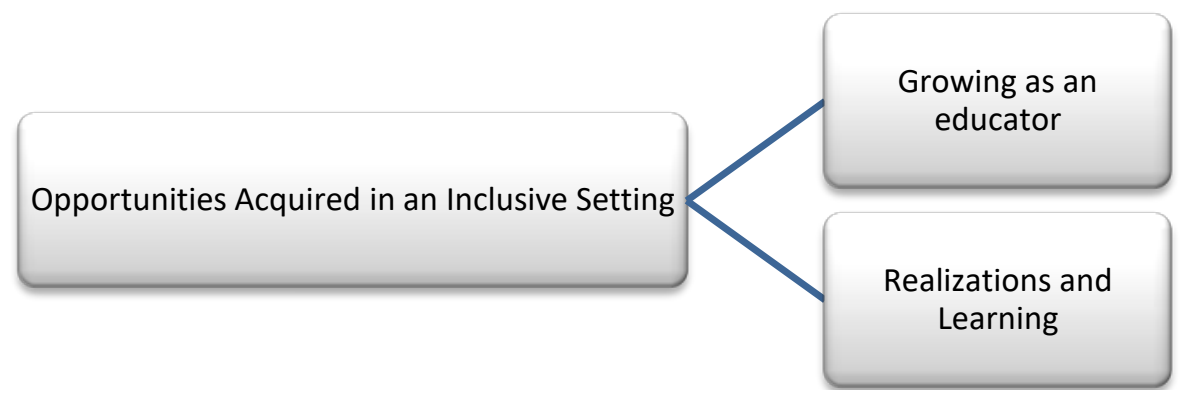

Figure 5. Opportunities Acquired in an Inclusive Setting.

\subsubsection{Growing as an Educator}

Despite of lack of training, preparation, and feelings of apprehension, all the ten (10) participants felt successful in the part as regular teachers in inclusive setting because they were committed to learn and grow in their profession. They were willing and driven to engage in their own research and also to learn from others. In addition, the participants stated that growing as an educator as one of the opportunities and privileges in teaching in an inclusive classroom setting based from their experiences. These statements revealed that although inclusion program is very hard, there are positive effects that the regular teachers involved acquires, such as change and improvement as a teacher and professional development as stated by the participants. Sears (2016) revealed that most of the inclusive teachers experienced some 
change in teaching style. Teachers became more of a facilitator and guide, were able to meet the needs of different learners and differentiate instruction, explored skills and concepts in more depth, began to offer more choices, and overall thought differently about the planning of lessons. Inclusive teachers affirmed teaching students with disabilities with inclusion made them better teachers because of the changes that occurred.

\subsubsection{Realizations and Learning}

All of the ten (10) participants used their real-life experience as a means of learning and realization. This included drawing from past experiences and learning from personal experiences and the education that they received from their current and daily experiences as regular teachers in inclusive setting. The following are the ideas shared by the participants as they stated that realization and learning as one of the opportunities and privileges in teaching in an inclusive classroom setting based from their experiences: RT5 said that "in dealing with children with special needs a heart because you have to exert extra effort to study the case of the child and put it into action. Receiving teachers must be provided with ample training regarding this and be supported also by the institution. They must be prepared mentally, emotionally and physically and most of all must have a heart for these special children, compassion is one armor they needed". RT3 added that "I have become more considerate with students with special needs" and RT4 revealed that "don't be scared in handling children with special needs because in a way they will teach you how to love and share more. It will be hard at first, but as long as you are willing you will learn nothing is impossible". While RT7 claims that “don't be contented in what you already know, there are more to learn and knowledge to gain. Take everything positively even if teaching them is very hard and challenging, I believe everything happens for a reason", RT8 added that "It is of valuing children with special needs, at the same time believing in their capabilities. I think we teachers, even if we experience challenges and hardship, we must try to explore, find more ways and technique and extend knowledge to fully help them start and pursue their dreams concurrently to others". Lastly from RT9 "Handling children with disabilities changed me in way that I have to think beyond my imagination for them to learn. This program taught me to become better teacher, a better educator and made me realize that children with disabilities have strengths and potentials like the regular students, even though I times I find teaching them to be difficult for me both physically and mentally, I still feel fulfilled after I have taught them”.

Overall, these real-life experiences clearly impacted their attitudes and beliefs about inclusion. Participants realized that consideration, patience, love for teaching, proper training, open minds towards inclusion, prior knowledge and background about the students with disabilities are all crucial components needed to successful implementation of inclusion. Allday et al. (2013) explained that in giving teachers a platform where they were able to share their perspectives of what is actually happening on inclusive classrooms, they were able to explain the strengths and challenges they have encountered. Participants used this platform to let needs be known that they could benefit both teacher and student. In just a short amount of time after learning about gifted students, these teachers have developed a deep concern for their well-being. This concern has even extended to other groups of students, making them better and more caring educators.

\section{Conclusion}

In conclusion, this study provided an understanding on how regular teachers described their real-life experiences in handling children with autism in inclusive setting and how do they describe their role and extent of involvement in handling children with autism in inclusive setting based from their real-life experiences.

First, the study showed that during the course of the implementation of inclusion in Saluysoy Integrated School, the regular teachers described their real-life experiences in handling children with autism by unveiling the different challenges faced by regular teachers such as the lack of training or seminar in handling children with autism, lack of administrative support; lack of teamwork among regular teachers and special education teachers; and increased in workload These challenges were the results of their real-life experiences that the school administrators should look and take an action by using it as basis for improvement plan of the school. If this is not addressed properly, the same experiences will be experienced by other regular teachers who handle other disabilities in an inclusive setting and worst; these challenges will cause a total failure of the program.

Moreover, they also described their real-life experiences in terms of the opportunities they have acquired while handling children with autism in an inclusive settings growing as an educator and their realizations and learning. Even though they find inclusion program to be very hard and challenging it still creates a positive effect with which regular teachers adapts to change and improve or professionally develops themselves. These positive effects pushed them into realization and learning. These real-life experiences clearly impacted their attitudes and beliefs about inclusion. Participants realized that consideration, patience, love for teaching, proper training, open minds towards inclusion, prior 
knowledge and background about the students with disabilities are all crucial components needed to successful implementation of inclusion.

Secondly, the different role and extent of involvement of a teacher in inclusive setting divulged throughout the experiences of the ten (10) regular teachers. It includes regular teachers: as curriculum planner and modifier; as a guardian or a protector; and as collaborator of inclusion. This signifies that although there are some challenges and problems that the regular teachers faced throughout the implementation of the program and some of the teachers have negative attitudes and perception towards inclusion program, the regular teachers still do not forget their role and the reasons why they are part of the program. They believe that they are responsible for ensuring that an adequate learning environment is established for children with autism as well as other students who are in inclusive setting.

\section{Recommendations}

The following recommendations are hereby presented, first a parallel study on the real-life experiences of inclusive education teachers handling other different disabilities including a bigger number of participants may be conducted. To put more rigor on the results of the study a focus group discussion, observation and diary aside from individual in-depth interview as added instrument to the study to capture more real-life experiences from the participants.

Secondly, seminars and trainings on inclusive education in collaboration with a special education expert should be conducted to address the needs of the teachers. And there must be a strategic staffing and planning in the selection of teachers who will serve as an inclusive teacher.

Lastly, characteristics of regular teachers in an inclusive setting should need a whole bucket of patience, should be open-minded for change and improvement; must love teaching; able to attend training related to special education by all means; oriented on the concept of inclusion and the characteristics of the students with disability; should be flexible; ability to look at things from all different angles; derive expectations based on the learner's needs, capacities and abilities; and can collaborate, learn from experience and develop relationship with other teachers. And a study with focus on the attitudes and perceptions of the school administrators to determine their perceptions and insights about inclusion program.

\section{Acknowledgement}

I wish to express a sincere gratitude to the ten women who so graciously agreed to participate in my study. In the course of gathering this material, interviewing the participants, and collecting the data, I had invaluable assistance from the women who volunteered to share with me their real-life experiences in handling children with autism. Without them, the completion of this study would not have been possible. I thoroughly enjoyed interviewing each one of them and learned so much from their "experiences" that I can share with all of you and with my own family in the years that follow. Their remarkable source of energy kept me motivated and smiling throughout this process.

I am grateful for the love, encouragement, and tolerance of Elmer B. Enriquez, the man who has made all the difference in my life. Without his patience and sacrifice, I could not have completed this paper. A special word of thanks also goes to my family for their continuous support and encouragement.

\section{References}

Abner, K. (2013). A Study of General Educators' Lived Experiences in the Inclusion of Elementary Students with Autism. Capella University. UMI Dissertation Publishing.

Allison, R. (2011). The Lived Experiences of General and Special Education Teachers in Inclusion Classrooms: A Phenomenological Study. Walden University. UMI Dissertation Publishing.

Allday, R. A., et al. (2013). Preparation for Inclusion in Teacher Education Pre-service Curricula. Teacher Education and Special Education: The Journal of the Teacher Education Division of the Council for Exceptional Children.

Arnilla, A. (2015). Lived Experiences of Filipino Grandparents Rearing Children with Autism: Its Implication to Special Education. Published Dissertation. University of Perpetual Health System Dalta. Las Pinas city.

Beasly, K. (2012). The Relationship between Secondary Teachers’ Attitudes toward Inclusion and Professional Learning. University of Phoenix. UMI Dissertation Publishing.

Broyard-Baptiste, E. (2012). Exploring How Special and Regular Education Teachers Work Together Collaboratively. Walden University. UMI Dissertation Publishing.

Cramer, A. (2014). Preservice Teachers' Attitudes and Efficacy Beliefs toward Inclusion of Students with Autism Spectrum Disorder in the Midwestern Region of the United States. Andrews University. UMI Dissertation Publishing. 
DepEd Order No. 26, Series of 1997. Department of Education. retrieved from deped.gov.ph.

Douglas, N. E. (2013). An investigation of attitudes and perceptions of pre-service teacherscompared to first year teachers toward inclusion. ProQuest LLC, Ed.D. Dissertation,The University of Mississippi.

Ely, S. (2013). A Qualitative Inquiry into the Experiences of GeneralEducation Teachers in Inclusion Classrooms. Capella University. UMI Dissertation Publishing.

Florian, L. (2013). Special education in the era of inclusion: The end of special education ora new beginning? Special Education.

Forlin, C., and Chambers, D. (2011). Teacher preparation for inclusive education: increasing knowledge but raising concerns. Asia-Pacific Journal of Teacher Education.

Fortain, J. (2015) An examination of Parents and Educators' Beliefs about the Expected Academic and Social Outcomes of Inclusion for Students with Autism Spectrum Disorder. Michigan State University. UMI Dissertation Publishing.

Giorgi, A. (2009). The Descriptive of Phenomenological Method in Psychology: A modified Husserlian Approach. Pennsylvania. Duquesne University Press.

Green, Jr. A. (2017). Perceptions and Attitudes of Special Education andGeneral Education Teachers towards Inclusion. Northcentral University. UMI Dissertation Publishing.

Haaland, L. (2011). A Phenomenological Study of Teachers' Experiences of Students with Learning Disabilities in Mainstream Middle School Classrooms. Northcentral University, Arizona. UMI Dissertation Publishing.

Heger, R. (2011). Psychosocial Coping Strategies of Inclusion Classroom Teachers as they Interact with English Language Students with Learning Disabilities. La Sierra University. UMI Dissertation Publishing.

Inciong, T., Quijano, Y., and Capulong, Y. (2007). Introduction to Special Education. Philippine Normal University. Manila.

Moustakas, C. (1994). Phenomenological research methods. Thousand Oaks, CA: Sage.

Osgood, R. L. (2005). The History of Inclusion in the United States. Washington DC: Galludet University Press.

Roberson, S. (2016). Teachers' Lived Experiences with Teaching Students Who Are Twice- Exceptional: A Phenomenological Study. Northcentral University. UMI Dissertation Publishing.

Robbins, S. (2014). Experiences of General Education Elementary Inclusion Co-Teachers in Successful Schools: A Phenomenological Study. Liberty University. UMI Dissertation Publishing.

Saunders, A. (2012). Inclusion of Middle School Students with Visual Impairments in the General Education Classroom. California Lutheran University. UMI Dissertation Publishing.

Sears, M. (2016). Experiences of Elementary Teachers using Inclusion Models to Serve Gifted Students. Liberty University. UMI Dissertation Publishing.

Solis, M., Vaughn, S., Swanson, E., and McCulley, L. (2012). Collaborative models of instruction: The empirical foundations of inclusion and co-teaching. Psychology in the Schools.

Sprowl-Loftis, P. (2013). General Education Teachers' Attitude towards Inclusion and Factors that Contribute to their Attitude. Capella University. UMI Dissertation Publishing.

Stilth, A. (2013). Principals' Attitudes toward Inclusion of Students with Disabilities. University of Phoenix. UMI Dissertation Publishing.

Sutton, J. (2013). Teacher Attitudes of Inclusion and Academic Performance of Students with Disabilities. University of Southern Mississippi. UMI Dissertation Publishing.

Vose, J. (2015). High School Paraprofessional Roles in the Inclusive Classroom. Northcentral University. UMI Dissertation Publishing.

Zeeck, K. (2012). A Phenomenological Study of the Lived Experiences of Elementary Principals Involved in Dual-Career Relationships with Children. University of St. Thomas, Minnesota. 


\section{Appendix A}

\section{Research Instrument (Interview Guide)}

\section{Real-Life Experiences of Regular Teachers Handling Children with Autism in Inclusive Setting}

\section{Part I: Demographic Profile}

1. What is your name and your designation as a teacher? (Optional)

2. Where did you graduate and your area of specialization?

3. Do you have professional training related to special education?

\section{Part Ii: Real-Life Experiences of Regular Teachers Handling Children With Autism In Inclusive Setting}

1. Based upon your experiences in teaching in an inclusive setting:

a. Do you believe that inclusion is easy as 1-2-3?

b. Do you believe that inclusion only benefits the students with disabilities?

c. How do you compare inclusion to mainstreaming?

2. Based upon your experiences in an inclusive setting, do you feel that regular teachers possess the expertise necessary to work with children with autism in an inclusive setting? Why do you think or consider this way?

3. Based upon your experiences in an inclusive setting, describe a time when inclusion was successful or unsuccessful. What key elements do you think contributed to the outcome of the experiences?

4. What has been your overall experience in relation to teaching in an inclusive setting?

5. What is or has been your role as a teacher in the inclusive setting?

6. Based upon your real-life experiences in an inclusive setting, what have you learned from it and what suggestions would you give someone who has just discovered that he or she may be working in an inclusive setting?

\section{Appendix B}

\section{LETTER OF REQUEST TO SCHOOL}

Dear Madam;

Good day!

I am Rowena V. De la Cruz, a SPED Class Adviser at SaluysoyIntegrated School. Presently, I am working on my research study entitled Exploring the Real-life Experiences of Regular Teachers Handling Children with Autism in Inclusive Setting. In line with this, I would like to ask your assistance by asking your permission from your good office that I be allowed to conduct my research study in Saluysoy Integrated School. The data will be gathered would be used primarily as a reference on special education.

Rest assured that any information obtained from your school for this research will be held confidential and only be used solely for this purpose.

Your positive response regarding this matter is highly appreciated. Thank you very much. 